\title{
INTERVENCIÓN DE LA PRESIDENTA DEL TRIBUNAL CONSTITUCIONAL
}

\author{
MARÍA EMILIA CASAS BAAMONDE
}

Rector Magnífico de la UNED, don Juan Antonio Gimeno

Ministro de Justicia, don Francisco Caamaño

Presidente Consejo Estado y Vicepresidente emérito del Tribunal Constitucional, don Francisco Rubio Llorente

Vicepresidente y Magistrados del Tribunal Constitucional

Sra. doña Graciela Soriano de García-Pelayo

Profesor don Antonio Torres del Moral Señoras y Señores

Mis primeras palabras han de ser de agradecimiento a la Universidad Nacional de Educación a Distancia, a su Departamento de Derecho Constitucional, y al Prof. Torres del Moral, por la organización de este acto en homenaje de Manuel García-Pelayo, quien fuera primer Presidente del Tribunal Constitucional. Este año, el 23 de mayo, se cumplió el centenario de su nacimiento y el 14 de febrero de 2010, en apenas unas semanas, se cumplirán 30 años de su nombramiento como Magistrado del primer Tribunal Constitucional y poco después, en julio, de su elección como primer Presidente, cargo que ejercería como es sabido hasta 1986.

El pasado 3 de octubre se cumplían 30 años de la Ley reguladora del Tribunal Constitucional, la Ley Orgánica 2/1979, de 3 de octubre, dictada en desarrollo del Título IX de nuestra Constitución, de la que a su vez hemos celebrado hace sólo unos días su trigésimo primer aniversario como norma reguladora de nuestra convivencia en paz y libertad como nunca antes habíamos disfrutado los españoles.

Coinciden, pues, las conmemoraciones del centenario del nacimiento del Presidente García-Pelayo y del 30 aniversario de la Ley reguladora del Tribunal Constitucional y en esta confluencia de fechas nada resulta más oportuno que rendir justo homenaje al primer Presidente del Tribunal Constitucional, y al Tri- 
bunal Constitucional mismo, circunstancias que propiciaron también un reciente acto en el Centro de Estudios Constitucionales y Políticos con ocasión de la presentación pública de la reedición de las obras completas de Manuel GarcíaPelayo; una tarea hecha con primor por dicho Centro, que ha incorporado algunos textos inéditos de García-Pelayo, lo que convierte esta reedición en referencia definitiva.

De la vida y obra del Presidente García-Pelayo han hablado ya quienes me han precedido en la palabra. Además, un amplio y representativo elenco de constitucionalistas, españoles y extranjeros ha escrito, espléndidamente, en el número 75-76 de la Revista de Derecho Político, que acaba de presentarse públicamente. En nombre del Tribunal Constitucional felicito a la UNED, a su Rector, Prof. Gimeno, y al Director de la Revista de Derecho Político, Prof. Torres del Moral, por este notable volumen monográfico dedicado a García- Pelayo. Un trabajo bien concebido, con distintas aportaciones sobre su vida y los temas que ocuparon la mayor parte de su intensa y productiva vida intelectual.

La de García-Pelayo es una obra investigadora que siempre ha estado unida a su actividad docente y que, por tanto, retomando las palabras de la semblanza que efectúa el Magistrado Aragón en la citada Revista, es la obra de un gran profesor universitario que ha extendido su magisterio a ambas orillas del Atlántico.

García-Pelayo cultivó el Derecho Político, con mayúsculas, a través del análisis lúcido de la historia, de la teoría política y del constitucionalismo, y nos ha regalado una serie de aportaciones teóricas decisivas para un público mucho más numeroso que el de los constitucionalistas. Algunas de sus obras, pese al tiempo transcurrido, siguen siendo insuperadas, como es el caso de su «Derecho Constitucional comparado", de hace casi 60 años.

Pero no me corresponde continuar destacando la categoría intelectual de García-Pelayo, de sobra conocida y ya expuesta en la laudatio del Prof. Rubio Llorente, sino expresar el reconocimiento y merecido tributo que el Tribunal Constitucional rinde a su primer Presidente, tanto por su labor insustituible en la puesta en marcha de un órgano constitucional nuevo, como por sus lúcidas y acertadas reflexiones sobre los rasgos esenciales de ese órgano imprescindible en el Estado de Derecho, democrático y constitucional; por tanto, en su desempeño como Presidente y como teórico del Tribunal Constitucional, que supo proyectar esta faceta sobre su desempeño aplicativo al forjar su identidad, al —en palabras del Presidente Tomás y Valiente- «instituir la institución».

Así, en la perspectiva de la puesta en funcionamiento inicial del Tribunal Constitucional, fue un indudable acierto la elección de García- Pelayo como su primer Presidente. Manuel García-Pelayo contó con el respaldo y el respeto intelectual de ese extraordinario primer colegio de Magistrados, así como con la eficaz 
colaboración de su Vicepresidente, Jerónimo Arozamena, para llevar a cabo una labor que requería unas cualidades extraordinarias: la constitución y funcionamiento de un nuevo órgano, creado por la Constitución de 1978 y virtualmente inédito en la historia (con el precedente único y escaso del Tribunal de Garantías Constitucionales), órgano que él mismo definiría como «coronación del Estado de Derecho». En palabras del Presidente Tomás y Valiente al asumir la Presidencia en 1986, concluida la primera de García-Pelayo, en esos primeros meses los Magistrados entonces nombrados fueron "coautores y actores de un apasionante proceso consistente en convertir al Tribunal en realidad organizada y actuante, partiendo del marco normativo contenido en la Constitución y en la Ley Orgánica».

También fueron esenciales los apoyos de los primeros Secretarios Generales del Tribunal (Juan Antonio Xiol, hoy Presidente de la Sala Primera del Tribunal Supremo, y los lamentablemente fallecidos Ángel Rodríguez y Javier Salas), así como de su jefe de gabinete y discípulo desde los años del exilio americano, Pedro Bravo, que desafortunadamente tampoco sigue ya con nosotros. Tras una primerísima instalación provisional en el Paseo de la Habana, el Tribunal se constituyó ya en su sede actual, que ha combinado la funcionalidad con la simbología que tanto gustaba a García-Pelayo, pues hoy nuestro edificio es para los ciudadanos la representación visual del Tribunal Constitucional.

A la Presidencia de García-Pelayo se deben los primeros pasos de la institución, la captación de los primeros Letrados, la definición de las prácticas y de los usos en las deliberaciones y en la redacción de las primeras resoluciones y de las primeras Sentencias, mantenidos hasta hoy, obviamente de nuestro constitucionalismo, con los cambios ineludibles exigidos por las nuevas regulaciones procesales y el comportamiento de la demanda de justicia constitucional. No es momento de resaltar las decisiones más relevantes del Tribunal en ese periodo — en materia de enseñanza, derecho de huelga, aborto y muchas más- que irían conformando una rica e imprescindible jurisprudencia constitucional que ha transformado muestra cultura jurídica.

En ese primer año de actividad jurisdiccional el Tribunal Constitucional ingresó unos 400 asuntos y dictó 41 Sentencias, una cifra que iría aumentando cada año inexorablemente hasta la cifra actual de cerca de 12.000 asuntos registrados y una media de 300 sentencias anuales. Cuando García-Pelayo dejó por voluntad propia la Presidencia y el Tribunal Constitucional en febrero de 1986, el Tribunal Constitucional ya había alcanzado su funcionamiento pleno, su velocidad de crucero, habiendo dictado en este periodo unas 4000 resoluciones, de las que más de 500 fueron Sentencias.

Dejó, como es bien sabido, el Tribunal Constitucional acosado por una indecente campaña de difamación que no pudo, desde luego, enturbiar su mag- 
nífica labor en la puesta en marcha de un órgano constitucional que, bajo su presidencia, ejerció impecablemente la tarea de defender y aplicar la Constitución que le confió el constituyente, guiándose en todo momento por el lema que en 1980 adoptó su Pleno y que figura en la medalla del Tribunal Constitucional: «Iustitia, Libertas, Concordia».

En el plano de las ideas y reflexiones que el Presidente García-Pelayo nos ha dejado en un artículo publicado en la primavera de 1981 en la Revista Española de Derecho Constitucional — cuyas líneas maestras había expuesto en su discurso de inauguración del Tribunal Constitucional el 14 de julio de 1980me limitaré a destacar algunas de ellas, bien que de manera muy somera, seleccionadas por su capacidad definitoria de la institución y su plena actualidad.

1. La jurisdicción constitucional es la garantía institucional básica del Estado constitucional de Derecho. Decía García-Pelayo «que la primacía de la Constitución, como la de cualquier otra normatividad, es jurídicamente imperfecta si carece de garantía jurisdiccional y, concretamente, si la constitucionalidad de las decisiones y actos de los poderes públicos no son enjuiciables por órganos distintos de aquellos que son sus propios actores». Por eso, afirmó, con razón, que «la inserción de la jurisdicción constitucional en la vida estatal asegura y perfecciona el Estado de Derecho, que es «su coronación», que el Estado material de Derecho exige una instancia equipada con la potestad de controlar la vinculación de los poderes superiores del Estado a las normas, valores y principios constitucionales, y consecuentemente que la garantía del Estado de Derecho precisa la complementación de la jurisdicción ordinaria por la jurisdicción constitucional, con la consecuencia de que el recurso de amparo devenga una institución constitucional indispensable para el Estado de Derecho».

En la concepción de García-Pelayo sobre nuestro Estado social y democrático de Derecho (art. 1.1 de la Constitución), «las medidas legislativas, gubernamentales y administrativas postuladas y orientadas por los correspondientes preceptos constitucionales darán vigencia y desarrollo al Estado social. Las Cámaras elegidas por sufragio universal son la máxima expresión institucional del Estado democrático. Y el Tribunal Constitucional, en fin, culmina el sistema del Estado de Derecho tal como ha sido ideado y configurado por nuestra Constitución». Así ha sido y así sigue siendo hoy.

2. La separación básica entre el poder constituyente y el poder constituido fue acertadamente señalada por García-Pelayo. Una división, subrayó con precisión García-Pelayo «cuya efectividad no se limita al momento de la elaboración o del establecimiento de la Constitución, sino que ha de manifestarse a lo 
largo de toda la vigencia de ésta ya que ello es condición de su propia existencia. Función del Tribunal es garantizar que los poderes constituidos actúen dentro del marco y de los límites establecidos por la decisión del constituyente tal como quedó objetivada en las normas constitucionales. En realidad, todas las competencias del Tribunal [de control de la ley, de resolución de conflictos de competencias y entre órganos constitucionales, de defensa última de los derechos fundamentales y libertades públicas de las personas] tienen como sentido custodiar esta dimensión primaria de la división de poderes». Esa función con ese sentido de custodia de la obra del poder constituyente de defensa y garantía de la Constitución la ha ejercido y ejerce en todo momento el Tribunal Constitucional.

3. Destacó García-Pelayo los rasgos característicos del Tribunal Constitucional como órgano jurisdiccional. Esos rasgos son ya bien conocidos, pero no puede caer en el olvido la contribución de García-Pelayo a su definición rigurosa en los años inaugurales de la jurisdicción constitucional.

Partía García-Pelayo de la regulación constitucional para afirmar que el Tribunal Constitucional «es un tribunal independiente, único en su orden y que, en coherencia con su carácter de órgano constitucional, no forma parte de la Administración de Justicia». Y añadía: «decide en forma de sentencia, con arreglo a unas normas preestablecidas y siguiendo un procedimiento contradictorio, sobre las pretensiones formuladas en términos de Derecho, que le someten las partes legitimadas para ello por la Constitución y la LOTC». Lo que le llevaba a concluir que es «un verdadero Tribunal, si bien posee unas notas peculiares —en parte consecuencia de su carácter de órgano constitucional- que le dan un perfil propio». Desarrollando a continuación esas notas, comenzando por destacar la función jurisdiccional que verdaderamente hace justicia a la naturaleza del Tribunal Constitucional: esa «función dentro del sistema de los órganos constitucionales es una función de control llevada a cabo por métodos jurisdiccionales. Tal control tiene como finalidad contribuir a que el dinamismo y la concurrencia de intereses, objetivos y valores inherentes a la vida política se mantenga dentro de los parámetros y límites constitucionales. Como parte de su función general de control, el Tribunal ejerce una acción de regulación entendiendo por tal aquella operación mediante la cual se neutralizan los disturbios y obstáculos al funcionamiento constitucional del sistema político. En este sentido puede ser considerado como una expresión de la idea del "poder neutro» enunciada por Constant, es decir, de un poder «no activo», pero independiente de los demás poderes y cuya sola función es evitar las desviaciones de éstos, si bien en la doctrina de Constant el titular de tal poder neutro era el monarca constitucional. El 
Tribunal, sin embargo, no es un órgano de control homoestático — para emplear un término de la teoría de sistemas- que asegure constantemente y por su sola operación el adecuado nivel de constitucionalidad del orden jurídico y de la acción de los órganos estatales, ya que no puede actuar por su propia iniciativa, sino solamente cuando es puesto en acción por los actores legitimados, lo que quiere decir que el orden jurídico puede albergar normas y actos inconstitucionales si tal inconstitucionalidad no es directa o indirectamente planteada ante la jurisdicción constitucional».

En su condición de Tribunal, el «Constitucional se tipifica también por los efectos y el sentido de sus sentencias. Sus decisiones, en cuanto que juzgan de la constitucionalidad de la acción de los órganos del Estado, no solamente tienen el valor de cosa juzgada, sino que vinculan a los poderes públicos, de modo que las conductas jurídicamente imputables a éstos deben ser conformes a las decisiones del Tribunal, en razón de lo cual sus sentencias han de ser publicadas en el Boletín Oficial del Estado».

En fin, el Tribunal Constitucional se define por su Ley Orgánica reguladora (art. 1.1.) como «intérprete supremo de la Constitución», «de donde se desprende que las interpretaciones del Tribunal en materia constitucional prevalecen sobre las llevadas a cabo por otros tribunales y, consecuentemente, que la jurisprudencia de éstos recaída sobre las leyes, disposiciones o actos enjuiciados por el Tribunal Constitucional se entenderá corregida por la doctrina derivada de las sentencias y autos que resuelvan recursos y cuestiones de inconstitucionalidad. Se comprende que la Ley Orgánica considere a la interpretación como el núcleo básico de la función del Tribunal, pues, en efecto, la función interpretativa tiene en materia constitucional más relevancia que en otras materias jurídicas, dada la mayor presencia de principios generales, de valores susceptibles de distinta interpretación y especificación, de cláusulas generales y de preceptos indeterminados, cuyos significados sólo pueden determinarse en cada caso y momento a través de las concretizaciones resultantes de la interpretación, por lo que se ha dicho con razón que si los límites entre la aplicación y la creación del Derecho son fluidos en todas las esferas jurídicas, tienden a confundirse plenamente en materia constitucional. En el ejercicio de la función jurisdiccional reservada al Tribunal Constitucional como intérprete supremo de la Constitución y dada la consiguiente preeminencia de su interpretación más autorizada y definitiva, «puede afirmarse - y así lo muestra la práctica de los Tribunales de otros países- que las motivaciones, la ratio o el discurso lógico de la sentencia, tiene con respecto al fallo una mayor importancia que en otras jurisdicciones. Si extremando las cosas suele decirse que lo importante de una sentencia es el fallo, de la jurisdicción constitucional podría decirse que lo fundamental es la motivación. 
Ello está en conexión con el sentido que suele asignarse al ejercicio de la función de la jurisdicción constitucional».

Estas consideraciones de García-Pelayo son de la mayor importancia para el adecuado entendimiento del Tribunal Constitucional y de la función privativa que le compete en el sistema constituido por la Norma primera y suprema.

4. Ya vislumbró García-Pelayo que sólo el Tribunal —y ningún otro órgano- tiene la potestad para establecer su jurisdicción o competencia. Dijo en tal sentido García-Pelayo que «si el Tribunal no posee la competencia de las competencias (que sólo corresponde a la Constitución), sí tiene, en cambio, dentro de los límites que le señalan la Constitución y la LOTC, el monopolio de la competencia para decidir sobre el legítimo uso de las competencias por parte de los órganos constitucionales.»

La falta de entendimiento de esta lógica, que define la posición institucional del Tribunal Constitucional como intérprete supremo de la Constitución, obligó al legislador a reformar la LO reguladora del Tribunal Constitucional, en concreto su art. 4, por la LO 6/2007, de 24 de mayo.

5. No dejó de reflexionar García-Pelayo sobre el papel del Tribunal Constitucional en la actuación conjunta de los Poderes del Estado. Para García-Pelayo el Tribunal Constitucional «incide en la dirección política del Estado, ya que su función es interpretar y aplicar con carácter supremo el Derecho constitucional, es decir, un Derecho de contenido político al menos en el sentido de que establece los principios configuradores de la unidad política nacional, normativiza los valores en que ésta se sustenta, establece límites y directrices para la acción estatal y, a través de la institución de órganos, de la determinación de sus competencias y del sistema de las relaciones entre ellos, regula la estructura y las funciones políticas del Estado. Un Derecho que establece las pautas normativas firmes dentro de las cuales acontece el dinamismo político, que crea el marco normativo fundamental de la acción política del Estado y que establece las vías de transformación de los poderes sociales en poderes estatales y de los valores políticos en normas vinculatorias o en directivas de la acción estatal». Advertía así que «las demandas planteadas ante el Tribunal son en muchas ocasiones (especialmente en los recursos de inconstitucionalidad y en los conflictos de competencias) la formulación en términos de litis jurídica de cuestiones o conflictos políticos, lo que tiene como consecuencia que sus decisiones, aun orientadas y fundamentadas en parámetros y valores jurídicos, tengan una significación y unos efectos no sólo para el ejercicio de las actividades políticas del Estado, sino también (en un Estado de partidos, como necesariamente lo es el Estado de- 
mocrático de nuestro tiempo) respecto a las posiciones de los partidos o agrupaciones de partidos. Para poner el ejemplo más manifiesto: si cincuenta diputados o senadores del partido o partidos minoritarios plantean un recurso de inconstitucionalidad, la sentencia del Tribunal, siempre fundamentada en razones jurídicas, si es afirmativa, rectifica la victoria parlamentaria de la mayoría; si es negativa, la ratifica, y entre ambos extremos caben resultados intermedios cuando la sentencia declara constitucionales algunos de los preceptos impugnados e inconstitucionales otros». Dejando de lado su significación y efectos sobre la dimensión extraestatal del sistema político y ciñendo sus consideraciones a la dimensión política de la acción del Estado, afirmó que «el Tribunal participa en las típicas funciones políticas de aquél, a través del ejercicio de sus competencias de control, pues el ejercicio de control sobre los componentes o relaciones de un sistema es una modalidad de participación en el funcionamiento del sistema».

En lo que hace específicamente al control "preventivo o a priori» que la Constitución (art. 95.2) y la LOTC (Título VII) establecen para los tratados internacionales no ratificados control preventivo que en el momento en que escribía el Presidente García-Pelayo, la LOTC extendía a los proyectos de Estatutos de autonomía y otras leyes orgánicas, «el pronunciamiento de su inconstitucionalidad por parte del Tribunal tiene como efecto la no admisión de sus normas o de algunas de ellas en el orden jurídico nacional. En este sentido el Tribunal, puesto en acción por los actores legitimados para ello, tiene una intervención en un momento dado del proceso legislativo y actúa como selector o filtro de entrada de normas en dicho orden jurídico.»

Como es sabido, en virtud de la reforma operada en la LOTC por la LO 4/1985, de 7 de junio, se suprimió el recurso previo de inconstitucionalidad (art. 79), supresión declarada conforme a la Constitución por la STC 66/1985. El Tribunal Constitucional ha seguido en los últimos años con interés el intenso debate doctrinal y político sobre la conveniencia (o no) de recuperar parcialmente esta figura. Pero continúo con las reflexiones del Presidente García-Pelayo: «En el caso del control llamado represivo o a posteriori, la declaración de inconstitucionalidad de los preceptos de una Ley o actos o disposiciones con fuerza de ley del Estado, de las Comunidades autónomas, de los tratados internacionales ya ratificados, así como de los órganos legislativos nacionales y regionales, produce la nulidad de tales preceptos y, por consiguiente, su expulsión del orden jurídico. Es sabido que el Tribunal no interviene en ninguno de los momentos del proceso legislativo (iniciado con la presentación del proyecto o proposición de ley y terminado con la sanción y promulgación), pero corrige a posteriori el resultado de tal proceso». Inmediatamente después la jurisdicción constitucional enriquecerá su actuación, como lo han hecho la generalidad de los 
Tribunales Constitucionales de nuestro entorno, con la práctica de las sentencias dichas interpretativas en aras de la satisfacción del principio de conservación de la ley y de libertad de configuración del legislador democrático con el límite insalvable del respeto a la Constitución, límite insuperable para el legislador y los demás poderes constituidos.

6. En fin, de especial importancia me parecen las reflexiones de García-Pelayo sobre la función integradora del Tribunal Constitucional. Sobre el presupuesto de que «nuestro tiempo se caracteriza por una acentuada tendencia pluralista no sólo de la sociedad, sino también del Estado», definía García-Pelayo el pluralismo como «un valor político y un componente necesario de la democracia del presente, elevado a principio constitucional en unos casos expresamente proclamado y en otros subyacente a distintas normas constitucionales». En su criterio, «testimonio de esta penetración de criterios pluralistas en el sistema estatal» eran "expresiones tales como «Estado de partidos», «Estado de organizaciones», «Estado de las autonomías», a lo que se añade que, como resultado de su crecimiento en complejidad, la misma organización interna del Estado está dominada por la fuerte presencia de tendencias pluralistas» $Y$ advertía: «una unilateral extensión del pluralismo podría conducir a un proceso acumulativo de atomización o factorialización y, en caso límite, a la destrucción misma de la estructura o sistema del que forman parte los componentes pluralistas. Tal posibilidad sólo puede ser neutralizada por la presencia de la integración, concepto caracterizado, precisamente, por la síntesis dialéctica entre pluralidad y unidad, por la superación de la antinomia entre la simple suma o agregación, de un lado, y la uniformidad o la socialización en pautas homogéneas, de otro; por la transformación en interdependencia del antagonismo entre independencia total y dependencia unilateral». Son así «factores integradores los destinados a realizar el proceso constantemente renovado de conversión de la pluralidad de componentes, de actos y de actores políticos en la unidad de acción y decisión del Estado. En este sentido, la participación en el proceso de integración es una de las dimensiones capitales de la acción política, y contribuir a su realización, una de las notas definitorias de los órganos constitucionales».

Pues bien, decía García-Pelayo, «es misión del Tribunal Constitucional afirmar la primacía de la Constitución y que la Constitución tiene decisiva función integradora que se muestra en la afirmación de unos valores que sustentan y orientan el proceso integrador (no es posible una integración sin la participación en unos valores) en el establecimiento de unas normas por referencia a las cuales la pluralidad de los preceptos se integra en la unidad fundamental del orden jurídico y la pluralidad funcional y territorial de órganos y de otras instituciones o 
actores de la vida política en la unidad de acción y decisión del Estado global, compuesto por el Estado central y las Comunidades autónomas a las que corresponde el ejercicio de ciertas funciones estatales».

Más allá de la mayor o menor actualidad de los casos concretos, acertaba a concluir, corresponde al Tribunal, a través de la solución de éstos, «desarrollar el Derecho constitucional y proporcionar la paz jurídica para el futuro, y, en fin, que entre sus funciones primordiales se cuenta el desarrollo ulterior del Derecho constitucional, esclareciendo y perfeccionando sus preceptos y contribuyendo con ello a la configuración de la realidad constitucional».

Resulta notable la clarividencia del Presidente García-Pelayo en subrayar algunos aspectos clave de la jurisdicción constitucional de tal manera que es posible reproducir sus análisis y reflexiones casi 30 años después sin necesidad de añadir mucho más que la confirmación y el enriquecimiento de sus planteamientos por nuestro devenir constitucional y, en su caso, la necesidad de su corrección cuando ese devenir se ha apartado de las proposiciones de García-Pelayo, es decir, de las premisas con que la normal expresión de la voluntad constituyente configuró la jurisdicción constitucional. En palabras del recientemente fallecido Profesor Héctor Gros Espiell, quien hace un recuerdo desde la amistad con García-Pelayo en el número monográfico de la Revista de Derecho Político hoy presentado, de García-Pelayo admiramos «no sólo la precisión con la que ha situado al Tribunal Constitucional, sino también la correcta visión de su futuro y de los problemas que habría de enfrentar, en el difícil equilibrio del Derecho y la Política».

La vida de nuestra Constitución — recién cumplidos 31 años — va indisolublemente unida a la del Tribunal Constitucional. El Tribunal Constitucional, en sus distintas composiciones, se ha guiado siempre por el empeño de hacer efectiva la Constitución y su primacía incondicionada en su aplicación cotidiana, en su preservación y en su continuidad hacia el futuro. El Tribunal Constitucional ha cumplido y cumple su tarea. Nosotros, los Magistrados actuales, hemos recibido un legado de nuestros predecesores - que reconocemos en este homenaje público a nuestro primer Presidente-, que, por ser interpretación de la Constitución y por su propio peso específico tiene que perdurar como patrimonio sustancial y, además, útil y fructífero para el fortalecimiento de nuestro Estado constitucional democrático y para nuestra convivencia actual y futura. La jurisprudencia del Tribunal Constitucional ha cambiado nuestra cultura jurídica, señaladamente en el campo de la defensa de los derechos - hoy por cierto se cumple el sexagésimo primer aniversario de la Declaración Universal de Derechos-, y determinado la organización del Estado, pese a la valoración crítica, legítima como no podía ser de otra manera, que algunas de sus decisiones hayan 
podido merecer a las partes y a la comunidad jurídica. La predisposición al futuro es la esencia de la Constitución y de la jurisprudencia constitucional, que es, a su vez, su complemento esencial y, como tal, garantía de la conservación y del futuro de aquélla, pacto de consenso y de convivencia, a la que en un proceso vivo actualiza continuamente mediante la interpretación y aplicación de sus preceptos, con el límite de la reforma constitucional, que excede de la misión de la jurisdicción constitucional, aunque también es, desde luego, cumplimiento de la Constitución. Muchas gracias a la UNED y a la Revista de Derecho Político por este merecido homenaje al Presidente García-Pelayo y a Vds. por su atención. 